\title{
DE HANDELAARS EN SUPERCARGO'S IN DE OOSTENDSE MOKA- EN INDIAHANDEL (1714-1735)
}

\author{
Jan PARMENTIER
}

\section{Inleiding ${ }^{1}$}

Kort na de Vrede van Utrecht (1713) toonden enkele Vlaamse handelaars een levendige interesse voor de direkte koloniale handel op Moka, China en de Indische kustgebieden ${ }^{2}$. Tot de winter van 1722-23 organiseerden particuliere kooplui de uitredingen, evenwel met belangrijke internationale kapitaalinbreng. Doch deze handelaars beconcurreerden elkaar dermate dat de winstmarges relatief snel slinkten. Daarom bleek de oprichting van de «Generale Indische Compagnie» (GIC) of de Oostendse Compagnie, op 19 december 1722 , een noodzaak ${ }^{3}$.

1. Deze bijdrage is een samenvatting van onze onuitgegeven licentiaatsverhandeling : «De Oostendse handel op de Arabische Zee en Voor-Indië (1714-1735)», Gent 1978-1979. Wegens plaatsgebrek behandelen we niet de maritieme organisatie van deze handel. Opmerking : de volgende afkortingen worden gebruikt in deze bijdrage : A.R. : Algemeen Rijksarchief, Brussel ; G.U.B. : Gentse Universiteit Bibliotheek ; I.O.L. : India Office Library, London ; R.A.B. : Rijksarchief Brugge ; R.A.K. : Rigsarkivet, København ; S.A.A. : Stadsarchief Antwerpen ; S.A.B. : Stadsarchief Brugge ; Admir. : Admiraliteit ; H.M. : Home Miscellaneous ; I.B. : Insolvente Boedelskamers ; G.I.C. : Generale Indische Compagnie ; R.v.Fin. : Raad van Financiën.

2. J. EVERAERT : De internationale en koloniale handel der Vlaamse firma's te Cadiz (1670-1700). Brugge, 1973. Er bestond een levendige indirecte handel naar West-Indië en Centraal-Amerika tijdens de regering van de zwakke Spaanse koning Karel II (1665-1700).

3. De oprichting van de GIC kwam enkele maanden te laat om nog schepen voor het komende seizoen uit te rustten. Aldus vertrokken de eerste compagnie-schepen pas in 1724 . 


\section{De handelaars en supercargo's}

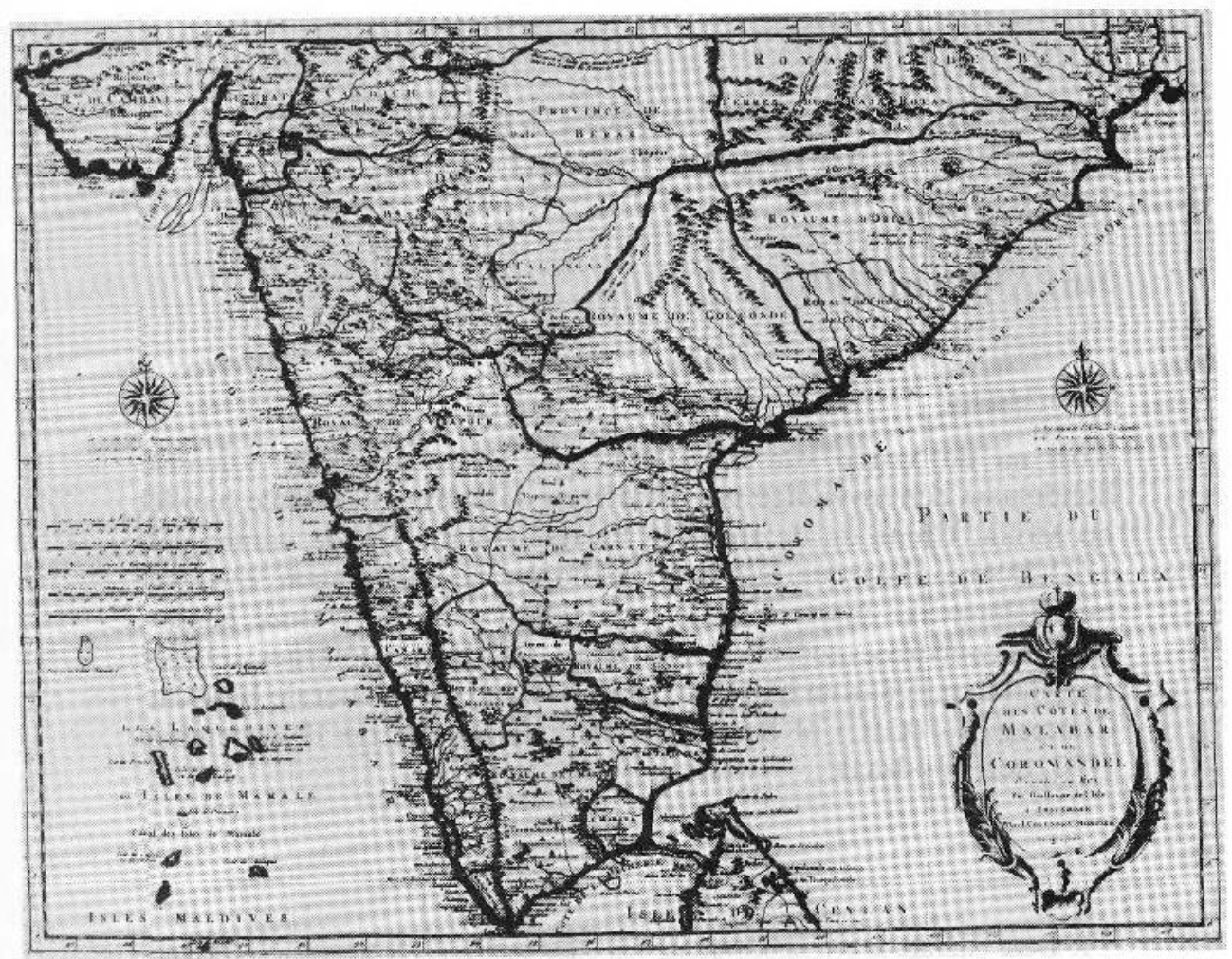


De commerciële activiteiten van de GIC concentreerden zich voornamelijk in Bengalen en in Kanton, omdat men er op hogere winsten kon rekenen in vergelijking tot de andere Aziatische markten. Sindsdien bleef de belangstelling voor India en de Rode Zee-havens beperkt tot enkele Oostendse «country-trade»-schepen ${ }^{4}$.

De compagnie kende slechts een korte levensduur (1735). Het belangrijkste motief voor de ontbinding van de GIC was de protectionistische economische politiek van de andere Europese naties. De Engelsen, Noord-Nederlanders en Fransen poogden met alle middelen een opkomende concurrent in de koloniale handel te fnuiken. Zij eisten de afschaffing van de GIC in ruil voor de aanvaarding van de «Pragmatieke Sanctie», welke Maria Theresia toeliet haar vader Karel VI op te volgen ${ }^{5}$.

Onze interesse gaat in het bijzonder naar de pre-compagnie-periode (1714-1723), en meer specifiek naar het internationale web van de Oost-Indiëhandel waarin de Zuidelijke Nederlanden een boeiende rol vertolkten.

\section{De reders en de handelaars}

Een schip naar Oost-Indië uitreden was een dure investering op lange termijn en bovendien een riskante onderneming. De resultaten van elke reis waren immers onvoorspelbaar. Om deze risicofacctor te verkleinen en te spreiden vormden reders en kooplui per uitreding associaties, die de nodige financiële middelen opbrachten.

We kunnen onder de Zuidnederlandse kooplui twee groepen onderscheiden die regelmatig aandrongen om scheepspaspoorten te bekomen. Vooreerst was er een Gentse associatie van de gebroeders

4. L. BOEVA : De factorij Banquibazar. Onuitgegeven licentiaatsverhandeling, Gent, 1978-1979.

De «country-trade» kunnen we omschrijven als de inter-Aziatische handel, die vooral tijdens de eerste helft van de 18 de eeuw o.l.v. de Europeanen opbloeide. De GIC-country-trade, georganiseerd vanuit Banquibazar in Bengalen, was verlieslatend.

5. De politieke en diplomatieke geschiedenis van de GIC is uitvoerig beschreven door M. HUISMAN : La Belgique commerciale sous l'empereur Charles VI. La compagnie d'Ostende. Bruxelles, 1902. 
Jacobus en Carlos Maelcamp, samen met hun zwager Jean-Baptiste Soenens. Hun belangrijke tegenhanger was een groep Antwerpse handelaars ; de vier gebroeders De Pret, waarvan vooral Jacomo en Arnoldo aan de Oost-Indiëtrafiek actief deelnamen, samen met hun zwager Paulo Jacomo Cloots. Daarnaast werkten er een aantal minder kapitaalkrachtige kooplieden regelmatig onderling samen, namelijk de Oostendenaars Thomas Ray, Mattheus De Moor en Pieter De Potter, de Bruggeling Dierick van Thienevelt en de Gentenaar Paulo De Kimpe. Twee Brugse pogingen om een schip naar Indië uit te reden werden geleid door enerzijds Jan-Baptiste Danckaert en anderzijds door Albert Van der Heyden. We gaan nu de kooplui en hun associaties afzonderlijk behandelen.

\section{a. Thomas Ray \& Co.}

Ray was van Ierse origine en Jacobiet. Hij moet reeds een tijd uitgeweken zijn naar onze gewesten, want hij bekleedde een aantal functies in het Oostendse stadsbestuur. Uiteindelijk werd hij in 1728 burgemeester van deze stad ${ }^{6}$.

In associatie met Jacques Schenaert (Antwerpen), Pieter Bouchaut (Gent), Louis Joly (Brugge) en Hollet de la Merveille (Saint-Malo), verkreeg hij op 24 april 1715 de twee eerste paspoorten (patenten) voor de «Charles VI» en de «Keyserinne Elisabeth». Doch hij heeft ze niet gebruikt?

In 1715 reedde hij samen met de Oostendse handelaar Pieter De Potter de «Sint-Mattheus» uit ${ }^{8}$. Daar Ray niet erg kapitaalkrachtig was, handelde hij tegen commissie. Hij kon zo de grootste risicoloze

6. I.O.L./H.M. no 74 , p. $385-387$ \& G.U.B. no 1859 . In 1716 wordt Thomas Ray vermeld als schepen.

7. SAA/ Privilegiekamer no 403, Missiven van de Jointe du Commerce en de Staten van Brabant aan de Antwerpse stadssecretaris Andries Melchior Van Kessel. Als bezwaren tegen deze onderneming stelden een aantal overheidsinstellingen dat deze twee schepen, die in Duinkerken werden uitgerust, bemand waren met buitenlandse officieren, zodat men niet wist onder welke jurisdictie deze vreemdelingen vielen. Tevens vreesde de overheid dat door deze uitredingen grote hoeveelheden zilver het land zouden verlaten.

8. AR/R.v.Fin, no 8603,11 okt. 1716. 
winst opstrijken, maar hij had geen of weinig belangen in het schip of zijn cargo. Wie de geldschieters van deze onderneming waren is vrijwel onbekend, wel woonden zij in Frankrijk. Waarschijnlijk waren het Fransen en Ierse of Engelse Jacobieten?.

Deze eerste uitreding was een sukses, want Ray en De Potter vroegen op 11 oktober 1716 een octrooi aan om een compagnie naar Oost-Indië te beginnen. $\mathrm{Zij}$ zouden optreden als directeurs, uitreders en commissionarissen (aan $2 \%$ ). Deze compagnie zou officieel gefinancierd worden door andere Zuidnederlandse handelaars, waaruit een beheerraad zou gekozen worden. $\mathrm{Zij}$ wensten in 1717 twee schepen uit te reden ${ }^{10}$. In het voorjaar van 1717 lagen de «Indian» en de «Marquis del Campo» vertrekkensklaar in de Oostendse haven. Met een cargo textielprodukten zou men koers zetten naar Cadiz en vandaar met een lading Spaans zilver naar Surate zeilen. Doch deze onderneming ging niet door wegens een tekort aan geld en krediet (waarschijnlijk te weinig aandeelhouders) en omdat er moeilijkheden (zonder specifiëring) gerezen waren tussen de voornaamste Franse investeerders. Beide schepen en hun heenladingen werden dan opnieuw verkocht ${ }^{11}$.

Thomas Ray gaf zijn pogingen nog niet op en kon de gebr. Maelcamp als financiers aantrekken om de «Prins Eugenius» door hem naar de Malabarkust te laten uitreden. Na deze geslaagde reis werd Thomas Ray als commissionaris aangezocht door Cloots en Crozat $^{12}$, om de openbare verkoop der ladingen van vier Chinavaarders uit St.-Malo, die in Oostende waren aangekomen (eind 1717-

9. IOL/H.M. no 74, p. 385-387. De familie Sarsfield uit Rouen, ook Jacobieten, investeerden in deze uitreding.

10. AR/R.v.Fin. no 8603,11 okt. 1716.

11. IOL/H.M. no 74 , p. 421,422 \& 430 . Brieven van Nunez aan de EIC, Amsterdam, 1717.

12. H. LUTHY : La Banque Protestante en France, de la Révocation de l'Edit de Nantes à la Révolution. Tome 1, p. 298-300. Paris, 1959. Crozat was een gekende Franse bankier, die een imperium in koloniale handel uitbouwde tijdens de eerste decennia van de $18 \mathrm{de}$ eeuw. Hij financierde de Franse slavenhandel en verwierf een monopoliepositie binnen de «Compagnie de Saint-Malo». 
voorjaar 1718 ), te verzorgen ${ }^{13}$.

Ondertussen trachtte Ray voor een tweede maal een compagnie op te richten, samen met Pieter De Potter en Dierick van Thienevelt. $\mathrm{Zij}$ wilden twee vrij oude schepen - de «Griffioen» en de «Hercules» in Zeeland opkopen, maar de prijs van $60.000 \mathrm{Zndl}$.FI. die André Peytier er voor vroeg konden zij niet betalen ${ }^{14}$. P.J. Cloots en zijn commerciële vrienden ${ }^{15}$ leenden de nodige financiële middelen, zodat één schip o.l.v. Godefroy de la Merveille naar de Coromandel zeilde. Deze uitreding werd een fiasco, waardoor Cloots nooit meer wenste samen te werken met Ray ${ }^{16}$.

Een volgende dubieuze onderneming zette Thomas Ray op met Paulo De Kimpe, Mattheus De Moor - de toenmalige burgemeester van Oostende - en een aantal Engelse kooplui. In Engeland liet men twee schepen, de «Cleyne Prins Eugenius» (een Chinavaarder) en de «Stahremberg», reisklaar maken ${ }^{17}$. In het voorjaar van 1719 ankerden beide schepen op de Oostendse rede om de boordpapieren in orde te brengen. Maar de plaatselijke gouverneur, Marquis del Campo, weigerde hen de nodige paspoorten te verschaffen ; waarschijnlijk omdat het grootste deel van de bemanning uit Ieren en Engelsen was samengesteld.

In het najaar van 1719 zijn deze twee Engelse schepen toch vertrokken onder keizerlijke vlag. Als uitreders gaf men de namen van de commissionarissen - eigenlijk stromannen - Ray, De Kimpe, De Moore en Jan-Baptiste Danckaert op. Ook bleef men vaag over de

13. AR/R.v.Fin. no 8603. Deze vier schepen zijn de «Martial», de «Grand Dauphin», de «Marquis de Maillebois» en de "Comte Pontchartrain». De aankomst van deze schepen veroorzaakte conflicten in de Antwerpse zijdemanufactures. De arbeiders vreesden immers hun werk te verliezen. (M. HUISMAN, op.cit., p. 88).

14. SAA/I.B. no 1684 Brieven van P.J. Cloots, 25-30 nov. 1717.

15. SAA/I.B. no 1684 Ibid., 2 dec. $1717,23 \& 24$ febr. 1718. Dit kapitaal werd geleend door 5 rijke handelshuizen ; 2 uit Londen (met P. Trehee en P. Hambly als woordvoerders), 2 uit Amsterdam (De Bruyn en A. Crop) en de Franse bankier Crozat.

16. SAA/I.B. no 1684 Brief van Cloots aan Ray, 9 dec. 1717 \& I.B. no 1685,20 sept. 1720. Dit was de "Keyser Carolus VI» met bestemming de Malabar- en Coromandelkust.

17. GUB/Ms. $1875 \&$ AR/Admir. no $575.79,16 \%$ van de bemanning op de «Cleyne Prins Eugenius» waren vreemdelingen, en op de "Stahremberg» 63,04\%. 
bestemmingen. De schepen zeilden naar Cadiz met textielprodukten. Deze cargo's verkochten ze daar en met het nodige Spaanse zilver vervolgden ze hun reis naar Surate en China (zie ook bijlage 3). Bij hun terugkeer in Oostende mochten ze aanvankelijk hun lading niet verkopen, omdat ze het verbod van Marquis del Campo genegeerd hadden ${ }^{18}$.

Tijdens dezelfde periode aanvaardde Ray een voorstel van P.F. Woelaert om de «Marquis del Campo» naar Surate en de Malabarkust te zenden ${ }^{19}$. Ray had weer moeilijkheden om in de Zuidelijke Nederlanden investeerders te vinden, zodat hij beroep deed op Engels kapitaal. Toen het schip op 13 februari 1721 Oostende bereikte, constateerde men dat het maar voor de helft volgeladen was. Dat wijtte men aan kapitaalsgebrek en aan de onervarenheid van de Vlaamse supercargo's ${ }^{20}$.

Zijn twee laatste uitredingen, namelijk deze van de «Stadt Gendt» (1720) en van de "Graef van Lalaing» (1721) die beiden Surate, Moka en de Malabar aandeden, waren winstgevend. Hij werkte hiervoor samen met Paulo De Kimpe en Mattheus De Moor ${ }^{21}$. Nadien zijn Ray en De Kimpe directeurs geworden van de GIC.

We mogen zeggen dat Thomas Ray \& Co. voornamelijk optraden als commissionarissen voor Engelse, Ierse en Franse handelaars die het monopolie van hun nationale compagnieën wensten te omzeilen.

18. GUB/Ms. 1875 \& AR/Raad van State no 1790 .

De uitreding in 1719 van een ander Chinaschip, de «Wirtemberg», door Ray en Co leverde $55 \%$ winst op (zie hierover J. MERTENS : Oostendse schepen naar Kanton (1719), in : Ostendiana, IV, Oostende, 1982, p. 19-37 en K. DEGRYSE : De Oostendse Chinahandel (1718-1735), in : Belgisch tijdschrift voor filologie en geschiedenis, LII, 1974, 2, p. 343).

19. SAA/I.B. no 1684 Brief van Cloots aan Woelaert, 3 okt. 1718. P.F. Woelaert fungeerde vaak als uitreder voor de Antwerpse kooplui.

20. SAA/I.B. no 1669 Correspondentie van Jacomo De Pret, 1721.

21. AR/Admir. no 563. 


\section{b. Paulo Jacomo Cloots}

Baron Paulo Jacomo Cloots werd geboren te Amsterdam in 1672, waar hij in de bankwereld carrière maakte. Marquis de Prié - de interim-gouverneur van de Zuidelijke Nederlanden - haalde hem naar Antwerpen. Daar huwde hij zijn nicht Johanna De Pret in $1717^{22}$.

In een brief aan Peter Hambly (Londen) beschreef hij zelf zijn handelsactiviteiten en inkomsten :

«...ick ben nogh coopman, nogh banquier, maer leeve als edelman, gelijck ick ben, van d'incomst van mijne landerijen, obligatiën en fondsen in Egelant, hebbende alleen in de Zuyt Zee $£ 8.000$ Sterl. capitael op mijn naem staen de rest houde in contant gelt, voor mijn enterprise op de Indias... ${ }^{23}$.

Hij stond goed aangeschreven aan het hof, waardoor hij vrij gemakkelijk - met steekpenningen - scheepspaspoorten kon bekomen. Op 20 oktober 1718 werd hij tot de adelstand verheven ${ }^{24}$.

Onder zijn directie vertrok, in januari 1718 , de eerste Oostendse Chinavaarder «Prins Eugenius» genaamd ${ }^{25}$. In feite was Cloots de deknaam voor een kapitaalkrachtig Europees consortium. De belangrijkste directeurs waren voor de Zuidelijke Nederlanden : P.J. Cloots en J. De Pret, voor Engeland : Edward Pearson, P. Hambly, A. Carter, P. Trehee en J. Acton, voor Frankrijk : Crozat en voor

22. A. de BURBURE de WESENBEEK : Une anthologie de la marine. Antwerpen, 1963 , p. 260.

23. SAA/I.B. no 1684 Brief van 26 okt. 1719.

Peter Hambly kan omschreven worden als een zeer aktieve Londense handelaar, die - buiten zijn interesse voor de Oostendse handel - betrokken was bij de directe handel op West-Indië. Ook ging zijn aandacht naar de slavenhandel en de South Sea Company (C. GILL : Merchants and mariners in the 18th century. London, 1961, p. 61).

24. AR/Kanselarij van de Nederlanden te Wenen, adelbrieven reg. no 770.

25. SAA/I.B. no 1684 Brief van 21 april 1718.

De internationale associatie rond Cloots leidde in 1718 de uitreding van de Chinavaarder «Huys van Oostenrijck». Dit schip zeilde in gezelschap van de «Wirtemberg» en de «Sint-Joseph». Een groep Antwerpse handelaars geconcentreerd rond François Schilders financierde dit laatste schip (Plantijn-Moretusarchief, no 279, briefwisseling van J.J. Moretus, 1720-21). 
Holland: D. de Bruyn en A. Crop ${ }^{26}$. De commissionarissen in Oostende waren Pieter François Woelaert (voor de uitreding) en Martinus Basius voor de verkoop) uit Haarlem ${ }^{27}$. E. Pearson, die ook supercargo was, en de Engelse kooplui waren de grootste aandeelhouders $^{28}$. Deze internationale associatie investeerde ook in de verlieslatende reis van de «Keyser Carolus VI» (1718).

Een derde uitreding van deze groep in 1718 was deze van de «Keyserinne Elisabeth». Hiermee speculeerde Cloots weer op een nieuwe handelsrichting : Moka, de bakermat van de koffiehandel ${ }^{29}$. Deze kleine compagnie floreerde goed tot in 1720 . In dat jaar poogde men de «Keyserinne Elisabeth» voor een tweede maal uit te reden, maar er rezen moeilijkheden tussen de Engelse vennoten en de anderen. Cloots vermoedde dat beiden zich elders hadden geëngageerd. De voornaamste oorzaak van deze moeilijkheden lagen in het feit dat de Engelse kooplui grote verliezen hadden geleden met de «South Sea Bubble»; verscheidene Londense handelshuizen gingen over $\mathrm{kop}^{30}$. Na dit voorval bleef P.J. Cloots meer op de achtergrond bij de uitredingen, voor een deel ook te wijten aan zijn slechte gezondheidstoestand.

Daarbuiten investeerde Cloots ook in de textielhandel op WestIndië, vooral via het handelshuis Cloots \& de Bruyn te Lissabon. Hij had tevens voor zijn prestige het Hof van Schilde opgekocht en voerde dan de titel Baron van Schilde, Paulo Jacomo Cloots overleed vóór $1728^{31}$.

26. SAA/I.B. no 1669 Brief van 8 juni 1720 .

27. SAA/I.B. no 1686 Brief van 23 okt. 1722.

28. Ibid., 4 juni 1720.

29. AR/Admir. no 575 .

30. SAA/I.B. no 1669 Brief van 13 nov. 1720.

31. SAA/I.B. no 1684-1690 : handelscorrespondentie van P.J. Cloots (1719-27). 


\section{c. De gebroeders De Pret ${ }^{32}$}

Bij de Indië-uitredingen treffen wij vier broers De Pret aan, namelijk Jacomo, Arnoldo, Paul Martino en Philippe Louis. De belangrijkste voor de Indiëhandel waren Jacomo en Arnoldo. $\mathrm{Na}$ in de jaren 1718-1720 betrokken te zijn bij de internationale associatie van Cloots, kwamen beiden op de voorgrond. In 1720 verlieten er onder hun directie twee schepen de Oostendse haven : de «Prins Eugenius» naar China en de «Stadt Weenen» naar Bengalen. Het werden twee winstgevende ondernemingen. Slechts een jaar later zeilde al het «Huys van Oostenrijck» naar China.

Omdat de onderlinge mededinging in de Oost-Indiëtrafiek te sterk groeide, en de winstmarges drukte, poogde P.J. Cloots de belangrijkste Zuidnederlandse handelaars te groeperen in een "societijt». Deze verzoeningspoging tussen de gebroeders De Pret enerzijds en de clan Maelcamp-Soenens mislukte. Bovendien ontstond er een breuk tussen Soenens en de Maelcamps. Soenens werkte dan, meer samen met de Antwerpse associatie.

De nieuwe commerciële relaties tussen Soenens en De Pret brachten twee uitredeingen tot stand, de «Keyserinne Elisabeht» (1722) naar Moka en de «Carel den Sesden» (1723) naar Bengalen. In de officiële documenten die aan de Admiraliteit moesten overgemaakt worden, stonden Soenens en Arnoldo De Pret telkens vermeld als respectievelijk uitreder en aankoper van het schip ${ }^{33}$. Jammer genoeg praaiden Algerijnse zeerovers de «Keyserinne Elisabeth» in het Kanaal, maar dit verlies maakten ze ruimschoots goed met de zeer geslaagde reis van de «Carel den Sesden» $(104,37 \% \text { winst })^{34}$.

Later vonden we Jacomo De Pret nog terug als GIC-directeur ${ }^{35}$. Binnen de beheerraad van de Oostendse Compagnie woedde er regelmatig een machtstrijd, doch de groep Cloots- De Pret kon steeds rekenen op de steun van Marquis de Prié. Zo wou Jacobus De

32. SAA/I.B. no 1664-1670 : handelscorrespondentie van Jacomo De Pret en I.B. no 1614-1621 : boekhouding van J. De Pret (1718-35)

33. AR/Admir. no 563.

34. AR/Kanselarij van de Nederlanden te Wenen, no 71, brief van 18 aug. 1725 .

35. M. HUISMAN, op. cit., p. 210. 


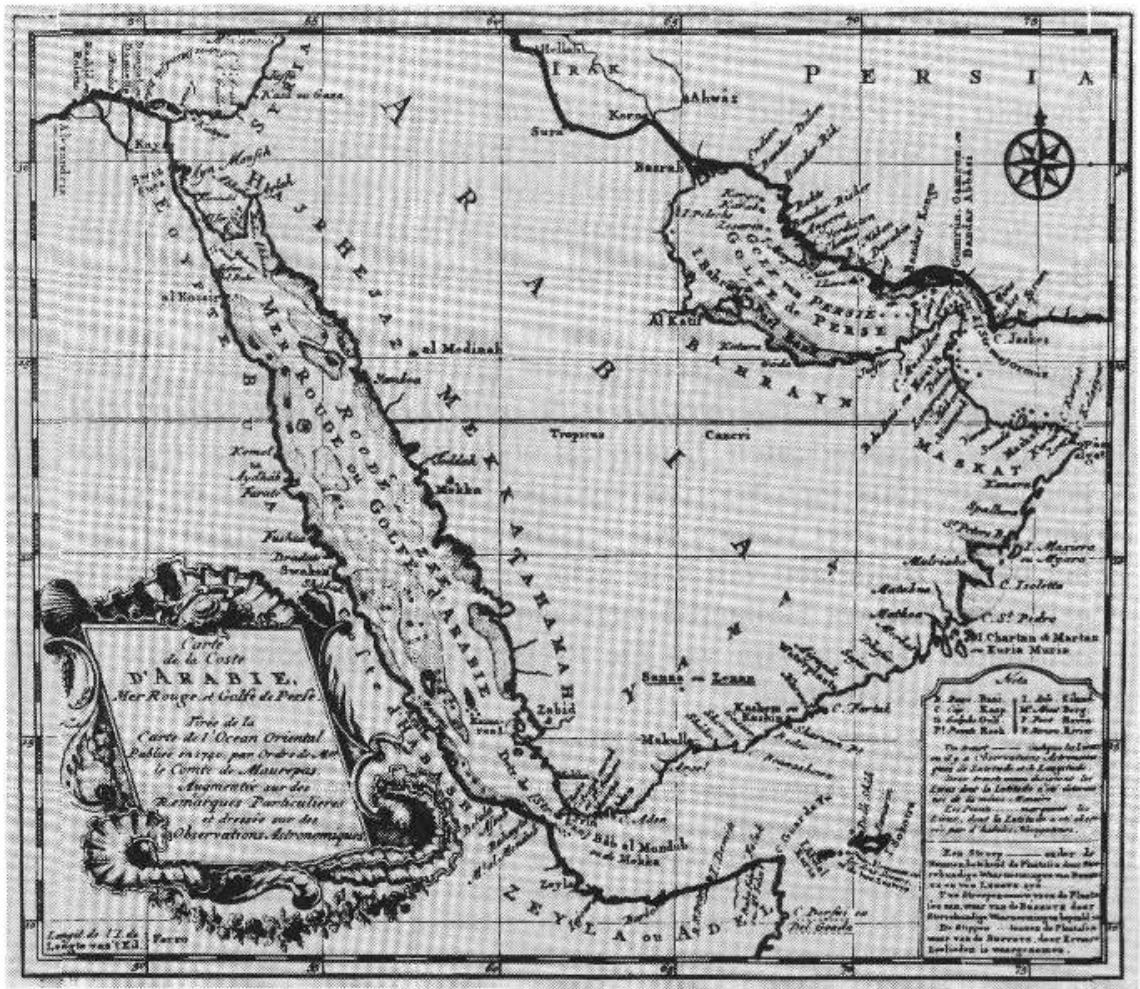


Coninck, die rijk en betrouwbaar was, niet samenwerken met De Pret, maar deze laatste had meer macht en liet, ondanks het protest van de andere directeurs, J. De Coninck vervangen. Aanvankelijk werd zijn broer Louis François De Coninck voorgesteld als nieuw lid, maar hij weigerde wegens zijn hoge leeftijd (de officiële reden) ${ }^{38}$. De Pret nam dan de plaats waar van De Coninck via een ingreep van de Prié ${ }^{37}$.

Jacomo De Pret had in de door ons bestudeerde periode een bloeiende Spanjehandel. Hij werkte hiervoor vaak samen met de Amsterdamse handelaars Craeywinckel \& van Susteren ${ }^{38}$. Hij investeerde ook in de Engelse staatsloterijen en, zoals Cloots, in de South Sea Company. Zijn broer Philippe Louis was aandeelhouder in de East India Company.

Jacomo De Pret interesseerde zich tevens voor diverse Franse staatsleningen. Getuige hiervan is de uitgebreide briefwisseling met Parijse correspondenten. Daarnaast onderhield hij een omvangrijke goederentrafiek met Noord-Frankrijk, Nantes, Bordeaux en SaintMalo. Bij De Pret vonden wij verschillende legerbetalingen terug ; het betrof zendingen van baar geld. Jacomo deed ook aan zuivere geldspeculatie via Hollandse negocianten. De diamanthandel bleek een ander facet te zijn van De Prets' veelzijdige commerciële en financiële activiteiten ${ }^{39}$.

Nadat de GIC verplicht werd officieel haar deuren te sluiten, investeerde dit Antwerps handelshuis, evenals andere belangrijke Zuidnederlandse kooplui, een behoorlijk kapitaal in de Zweedse

36. SAA/I.B., no 1686 Brief van P.J. Cloots, 4 dec. 1721. Een associatie rond De Coninck rustte slechts één schip uit, de «St.-Joseph» (1721), naar China, L.F. De Coninck werkte steeds goed samen met de Maelcamps.

37. GUB/ Microfilms Wenen, Berichte (DDA 13-86) Marquis de Prié aan Karel VI, 13 april 1723.

38. SAA/I.B. no 1664-1670 \& L. MICHIELSEN : Kapitalisme in Antwerpen in de 18de eeuw, doctoraatsverhandeling, 1935.

39. SAA/I.B. no 1703-1704. De familie De Pret was voornamelijk tijdens de $17 \mathrm{de}$ eeuw aktief in de diamantwereld. Voor verdere informatic verwijzen we naar E. DE COSTER : De diamanthandel te Antwerpen in de XVIIe eeuw gezien vanuit de geschiedenis van de firma's Wallis-du-Jon, Boon en Forchoudt, in : Album Verlinden, Gent, 1975 , p. $95-116$. 
Oost-Indië Compagnie, de Deense Aziatische Compagnie en WestIndië Compagnie. Het Zweedse luik, zowel de participatie door aandelen als de bodemarijcontracten, werden besproken door C. $\mathrm{Koninckx}^{40}$. Al de Zuidnederlandse aandeelhouders in de Deense Aziatische Compagnie (DAC) investeerden voordien in de $\mathrm{GIC}^{41}$. Deze Scandinavische interesse beperkte zich evenwel tot de Antwerpse en Gentse commerciële kringen ${ }^{42}$. Ook voor de winstgevende bodemarijen op Chinareizen bestond er grote belangstelling. Zo nam, in 1735-36, een Antwerpse associatie (J.J. Moretus, Francisco Schilders en Jacomo De Pret) verscheidene bodemarij-brieven op voor de «Kongen af Danmark» en de «Sleswig». Deze geïnvesteerde sommen schommelden tussen 1.000 en 8.000 Znd. fl.w.g. ${ }^{43}$.

\section{d. De gebroeders Maelcamp en Jean-Baptiste Soenens ${ }^{44}$}

Charles (Carlos) Maelcamp ( ${ }^{\circ}$ Gent 23-11-1677 - $†$ Gent 23-03-1763) en Jacobus Maelcamp ( ${ }^{\circ}$ Gent 25-10-1683 - † 24-02-1741) waren, samen met Joseph Gheselle en Houlaert uit Brugge, de eerste Vlaamse kooplui die een schip, de «Charles Galleye» (1715), naar

40. C. KONINCKX : Zuidnederlandse deelname in de Zweedse Oost-Indische Compagnie 1731-1786, in : Handelingen van de Koninklijke Zuidnederlandse Maatschappij, dl. XXI (1978), p. 121-126 en «The First and Second Charters of the Swedish East India Company (1731-1766)", Kortrijk, 1980. Een bodemarij is een contract waarbij een financier aan een reder/kapitein/supercargo een som geld leent om zijn schip uit te rusten of om handel te drijven, met de bepaling dat indien het schip behouden terugkeert de lener het kapitaal moet terugstorten samen met een aanzienlijke intrest, die schommelt naargelang het risico dat aan de reis verbonden is (reisdoel en marktcondities). Gaat het schip verloren dan verliest de ontlener zijn kapitaal.

41. SAA/GIC no 5647 «Liste des intéressés (1723-1726)» \& L. HUISMAN, op. cit., p. 242. De participanten in de DAC vinden we terug in RAK/ Danske Kancelli D147 (1732-1747).

42. RAK/ Danske Kancelli D147. De groep Maeclamp bezat liefst 52 DACaandelen op een emissie van 1600 .

43. Plantijn-Moretusarchief Antwerpen no 1214-15 bodemarijbrieven bij de DAC (1735-36) en correspondentie tussen Paul Jacobs en Frans Faeddesen (1735-37).

44. Hier bespreken we enkel de Oost-Indiëhandel van deze Gentse kooplui. Andere commerciële activiteiten, investeringen en onroerende bezittingen van deze associatie worden uitvoerig toegelicht in $\mathrm{H}$. COPPEJANS-DESMEDT : Bijdrage tot de studie van de gegoede burgerij in Gent in de 18 de eeuw. Brussel, 1952. 
Oost-Indië uitreedden ${ }^{45}$. Bij deze eerste reis ging men zeer omzichtig te werk. Het schip werd in Londen gekocht onder de mom dat het voor de Casa de la Contratacion van Cadiz was en gedestineerd naar Zuid-Amerika. De bemanning van Engels. In Cadiz werd met Hollandse passen Zuidnederlandse manufacturenprodukten (vnl. textiel) verkocht om een zilverlading in te $\operatorname{slaan}^{46}$. $\mathrm{Na}$ aan de Malabar, te Goa en te Surate vooral peper aangeschaft te hebben, verhandelde J. Gheselle (kapitein en eerste supercargo) een deel van dit cargo in Gibraltar (oktober 1716). Het schip werd in Cadiz van de hand gedaan. De resterende peper, samen met Spaanse waren (olie, wijn, fruit), kon men in Oostende aan de man brengen ${ }^{47}$. Na deze geslaagde uitreding begonnen de Maelcamps hun Indiëhandel uit te breiden $^{48}$.

Samen met Ray werd in 1717 een tweede winstgevende reis naar de Malabarkust ondernomen ${ }^{49}$. In 1719 rustte de Maelcamps, met financiële inbreng van Jean-Baptiste Soenens $\left({ }^{\circ}\right.$ Gent 17-07-1676 - $\dagger$ Gent 23-04-1746), drie schepen uit. de «Prins Eugenius» en de «Concordia» naar Malabar en Surate, en de "Franciscus-Xaverius» naar China. De Chinavaarder bleek onverwacht verlieslatend ${ }^{50}$. Ook de winstmarge van de «Concordia» was miniem en de «Prins Eugenius» werd gekaapt ${ }^{51}$. Daar hun volgende Indiëvaarder de «Stadt Oostende», ook gepraaid werd wensten de Maelcamps zich

45. AR/R.v. Fin. no 8603 en IOL/H.M. no 74, p. 473.

46. Daar het aan keizerlijke onderdanen verboden was handel te drijven met Spanje, gebruikte men Engelse en Hollandse paspoorten (IOL/H.M. no 74, p. 429, Brief uit Parijs aan Woolley, 1717).

47. AR/R.v. Fin. no 8603 .

48. IOL/H.M. no 74 p. 387 Brief van de Britse consul te Oostende aan het Secret Committee, sept. 1716.

49. Dit was de «Prins Eugenius», kapitein en eerste supercargo J. Gheselle.

50. IOL/H.M. no 74, p. 481-483 Brieven uit Barbados, 14 april 1721. In maart 1721 legde de «St.-Franciscus-Xaverius» te Barbados aan. Na onderhandelingen tussen de Engelse supercargo Mounteney en Samuel Cox, commandant van Barbados, mochten de «Oostendenaars" hun pacotilles verkopen onder het valse voorwendsel dat ze een te kort aan baar geld hadden om hun schip te herstellen. De EIC vermoedde dat ook Engelsen deze uitreding financierden.

51. AR/Admir. no. 563. 
toe te leggen op de Chinahandel. In 1721 vroegen ze een octrooi aan om twintig jaar lang exclusief schepen naar Kanton te mogen zenden $^{52}$. Dit lokte natuurlijk protest uit van de invloedrijke Antwerpse associatie, zodat de Maelcamps het monopolie niet kregen. De Gentenaars hadden weer weinig sukses met hun twee uitredingen in 1721 ; het cargo van de «Sint-Pieter» leverde slechts $12,7 \%$ winst op, en de Chinavaarder «Flandria» confisceerden de Engelsen nabij Fort Bencoulen $^{53}$. Tijdens $1722-23$ zond de Gentse associatie nog drie schepen naar China, met hoge winsten deze $\operatorname{keer}^{54}$. J. Maelcamp en Soenens brachten het ook tot directeurs van de GIC.

\section{e. De Brugse handelaars Jan-Baptiste Danckaert en Albert Van der Heyden $^{55}$}

In 1720 werd een kleine onderneming voor handel op Oost-Indië opgezet tussen de Hollanders de Roy en de Wit, met de hulp van Frans kapitaal. J.B. Danckaert acteerde enkel als commissionaris om de uitreding en de hoofdpapieren van hun schip de «Flandria» te verzorgen (zie illustratie 3$)^{56}$. De voorgestelde bestemmingen waren Borneo, Surate en Moka. Maar wanneer het schip op 9 juni 1720 Texel verliet - dit Waddeneiland fungeerde als voorhaven van Amsterdam - werd het door de Amsterdamse Admiraliteit aangeslagen en geconfisceerd. Deze mislukking betekende meteen het faillissement voor Danckaert. De belangrijkste Franse aandeelhouders waren de Parijzenaars Jean Cottin en d'Arraz ${ }^{57}$. Albert Van der

52. AR/Kanselarij van de Nederlanden te Wenen no 639, p. 219-223.

53. AR/R.v. Fin. no 8604 .

54. K. DEGRYSE, op. cit. p. 343. De uitredingen van de «Keyzerinne» (1722), de «Sint-Joseph» (1723) en de «Marquis de Prié» (1723) leverden respectievelijk winstmarges van $80 \%, 83 \%$ en $104 \%$.

55. M. HUISMAN, op cit., p. 212 \& 241.

56. De activiteiten van A. Van der Heyden die geen betrekking hadden op de Indiëhandel worden ten dele vermeld in de "Staten van Goederen van Albert Van der Heyden» (SAB no 8627, 20 mei 1729).

57. De Pret schreef hierover aan Soenens : «Ick verstaen heden dat hij (Danckaert) noch sijne familie niet een stuyver int schip hebben" (SAA/I.B. no 1669, 12 nov. $1720)$. 
Heyden werd met François Van den Bussche als directeur aangesteld om de schulden te vereffenen aan Danckaerts' crediteuren ${ }^{58}$.

Albert Van der Heyden ( ${ }^{\circ}$ ? Brugge - $\dagger$ 22-05-1728 Brugge) en Jean-Baptiste Houwens des Gardins, afgevaardigde van de Compagnie van de Demer, wilden in 1720 een compagnie voor de Indiëhandel oprichten. Van der Heyden zou de directie van de compagnie in Brugge waarnemen, terwijl Houwens des Gardins het kantoor in Wenen zou leiden. Er bestond veel interesse bij de Weense topfunctionarissen voor dit project, zodat beide directeurs hoopten dat dezen hun het nodige startkapitaal zouden bezorgen. Zo hadden ze reeds in het najaar van 1721 voor 128.000 Znd. fl.w.g. intekeningen te Wenen ${ }^{59}$.

Op 10 januari 1721 verkreeg Van der Heyden een patent om de «Stadt Brugghe» uit te reden. Kapitein zou Carolus Notebaert worden (een fictieve kapitein). Als eigenlijke kapitein werd Jean de Roy, die ook directeur was van de «Flandria», voorgesteld en als supercargo Herman van Pleuven. Deze twee protestantse Hollanders woonden reeds in Brugge. Men wenste handel te drijven op de Malediven (kauris), Malabar (peper/textiel) en dan naar Nagoura, aan de Coromandel (textiel). In deze Indische handelsplaats hadden de Europeanen nog geen factorijen opgericht ${ }^{60}$.

Het schip lag reeds enige tijd te Brugge (april 1721) wanneer de ervaren kapiteins Tobin en Gheselle vaststelden dat de «Stadt Brugghe» ongeschikt qua tuigage was om een lange Indiëreis te ondernemen $^{61}$. Hierover hield men op 25 september 1721 een algemene vergadering van de directeurs; daarbij waren de Hollanders Bartolomeus De Wit en van Pleuven, en de Bruggelingen Van der Heyden en François Van den Bussche. Er waren reparaties nodig aan het schip om het zeilvaardig te maken, en waarschijnlijk liep de samenwerking tussen de initiatiefnemers onderling niet meer gesmeerd. Daarom besloten ze de reis uit te stellen. Bij een eventuele

58. SAB no 8627,20 mei 1729.

59. AR/ Secretarie van State en Oorlog, no 2185, p. 53-54.

60. AR/Admir. no 563 en R.v. Fin. no 8604.

61. SAA/I.B. no 1670 Brief van 28 aug. 1721 . 
nieuwe uitreding zou men naar nieuwe geldschieters zoeken en met andere directeurs werken ${ }^{62}$. Hiermee viel een veelbelovend project in het water.

De «Stadt Brugghe» werd dan op 15 april 1722 aan Daniël de Bruyn uit Amsterdam verkocht ${ }^{63}$.

\section{De supercargo's}

De supercargo's of de handelaars aan boord van de schepen zorgden voor de heen- en retourladingen. Ze bekleedden een sleutelpositie tijdens de vooruitredingen omdat de Zuidnederlanders geen rendabele factorijen konden verwerven, die de taken en verdiensten van de supercargo's zouden beperken ${ }^{64}$.

Deze zeer lucratieve functies trokken talrijke buitenlanders aan ; van de 54 teruggevonden supercargo's kwamen er 17 uit Engeland, 7 uit Frankrijk, 6 uit Ierland en 3 uit Noord-Nederland. Toch troffen we 21 Vlaamse supercargo's aan, maar slechts enkele onder hen werden aangeworven als eerste of tweede supercargo ${ }^{65}$. Vooral de gebroeders Maelcamp engageerden vrij veel Vlamingen (17 van de 21).

De mogelijkheid om op korte tijd fortuin te maken vormde voor de vreemdelingen de belangrijkste aantrekkingspool. De Zuidnederlandse handelaars stonden zeker niet weigerachtig om ze aan te werven, op voorwaarde dat ze reeds ervaring hadden in overzeese handel. Zo kwam tot uiting dat Edward Pearson een expert bleek op de Arabische koffiemarken, en Alexander Hume de meest winstge-

62. Ibid. Brieven van $25 \& 28$ sept. 1721.

63. SAA/I.B. no 1671 Brief van 16 april 1722.

64. In 1719 verkregen de Zuidnederlanders een factorij te Cabelon (Sadatpatnam) - dankzij Franse diplomatieke en financiële hulp uit Pondichéry - aan de Coromandelkust (zie illustratie 1). Voornamelijk door het feit dat het onmogelijk was om een geschreven factorij-concessie te bekomen, bleef Cabelon afhankelijk van de grillen van de plaatselijke Moorse gouverneurs. Daardoor slaagde men er niet in deze interessante haven uit te bouwen tot een commercieel centrum.

65. AR/R.v. Fin. no 8604 en Admir. no 563. Enkel de Gentenaar Joseph de Gheselle stond kwalitatief op dezelfde hoogte als de buitenlanders. Als eerste supercargo ondernam hij drie suksesvolle reizen naar India. 
$N^{\circ}$

\section{ARMEMENT \& CARGAISON}

d.Un Navire de Bruges munie de Patente de Sa Majefte Impcriale E Catlsolique,

\section{LA FLA NDRE d'Environ 450. Thonneaux.}

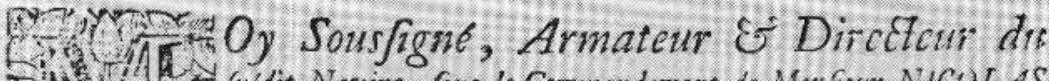

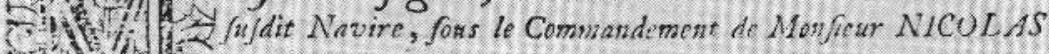
7.1.2 SCARPENTIER de Briges qui va partir dans ce fungle:

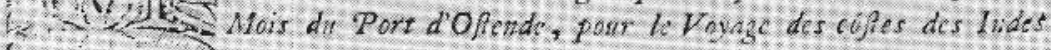
Orichtales ricontrois avoin seccu de

la Sominc de

Flarins Aructit de

Clange pour la quelle je declare avoir intereffe le dit

de la dite Somme dans la dit Navire Armenent Ef Cargaifon, pour participer a proportion de fon intereft au profit, chl irote.

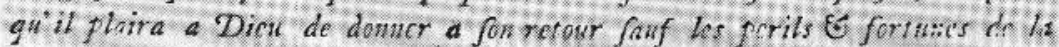
Mer: approurvant le dit Sicur comme it fait defaprefent tout ce giy a che,

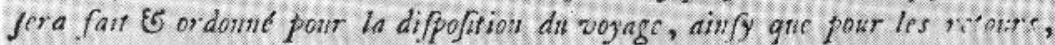
lequel dit Sicur interffe fe rapportera ait Compre general, quy en awe cie arrefle apres la vente generale os repartition de ce gitl viendra a clasgue Intcrcffic a proportion des fomzas qu' il y aura mifes, Is quel Compte io temdray akx trois principawx Interefez, fait a Rruges 
vende textielladingen naar Oostende bracht ${ }^{66}$. Ook jonge, beginnende kooplui poogden hier een loopbaan uit te bouwen. Bijvoorbeeld John Gould, een Ierse vriend van Thomas Ray, doch zonder gunstige perspektieven werkzaam in de East India Company. Ray nam het risico hem te aanvaarden als eerste supercargo op de «Graef van Lalaing ${ }^{67}$. Zonder veel ondervinding wist Gould tegen een redelijke prijs een retourlading aan te kopen. Dankzij deze behoorlijke start kon hij carrière maken binnen de GIC, maar de compagniedirecteurs vonden zijn financiële eisen te hoog ${ }^{68}$. Hij vestigde zich in deze periode te Oostende als handelaar en werd zelfs schepen in deze stad in $1745^{69}$.

De vergoedingen uitbetaald aan de voornaamste supercargo's konden soms zeer hoog zijn. De «pacotille»- hun eigen handel overzee - mocht, naargelang de functie, in 6 tot 12 kisten verpakt en opgeslagen worden in het ruim. Elke kist had een, volgens het aanwervingskontrakt bepaald, volume van $0,376 \mathrm{~m}^{3}$. Bovendien ontving elke supercargo een "gage» - een loon - en een "provisie» - een commissieloon - van 1 tot $5 \%$ op de verkoop van de lading ${ }^{70}$.

Via de boekhouding van Jacomo De Pret kennen we de opbrengst van pacotille-vendities uit drie Indiëvaarders. Tijdens de Mokareis van de «Keyserinne Elisabeth» (1718) mochten de Londenaars Edward Pearson en James Acton - resp. eerste en tweede supercargo - een pacotille van 12 ton aankopen. De openbare venditie van

66. AR/Manuscrits Divers no 4361 Brief van Jan van Leeuwen (VOCfactorijhouder te Moka) aan Christoffel Van Swoll (gouv.-gen. te Batavia), 20 aug. 1719.

67. AR/Admir. no 665-666 Scheepsjournaal van de «Graef van Lalaing» (17211723) en SAA/I.B. no 1672-1673 Correspondentie van J. De Pret, 1723-24.

68. Over het tekort aan ervaren supercargo's schreef De Pret : «c'est dommage que notre Pays nous fournit si peu de sujets» (SAA/I.B. no 1673, 15 sept. 1724).

69. SAA/GIC no 5625 en J. BOUWENS : Nauwkeurige beschryving der oude en beroemde zeestad, Oostende, gelegen in oostenryksch Vlaenderen. Brugge, 1792, p. 113.

70. SAA/GIC no 5520 en I.B. no 1616 Boekhouding van J. De Pret (1724-25). Bruikbare en boeiende informatie over de supercargo's op de Oostendse Chinaschepen is bijeengebracht door K. DEGRYSE : op. cit., p. 306-347. 
deze goederen bracht $25.708 \mathrm{Znd}$.fl. op of $4,5 \%$ van totale verkoop van de lading. Met hun provisie van $2 \%$ verdienden ze 11.324 Znd.fl. Dit betekent dat, rekeninghoudend met de globale nettowinst van $87,3 \%$, Pearson en Acton 23.232 Znd.fl. aan deze reis overhielden. Dit bedrag mogen we als een normale vergoeding beschouwen, maar toch vrij laag in vergelijking tot de inkomsten bij supercargo's op de particuliere China-schepen ${ }^{71}$.

Tijdens de jaren 1720-24 ondernamen Alexander Hume en John Harrison twee zeer winstgevende reizen naar de Coromandelkust en Bengalen, met de "Stadt Weenen» en de «Carel den Sesden". De pacotille-venditie van de «Stadt Weenen» bedroeg 107.136 Znd.fl. en de provisie a $5 \% 31.407 \mathrm{Znd}$.fl. Bovendien investeerden Hume en Harrison 21.000 Znd.fl. in deze uitreding en ontvingen ze als aandeelhouders een dividend van 11.900 Znd.fl. Het globale deel van alle pacotilles in de cargo-verkoop was uitzonderlijk hoog voor een Indiëvaarder : $24,7 \%$.

Met de reis van de «Carel den Sesden» werden Hume en Harrison de best betaalde supercargo's uit de pre-compagnie periode. De verkoop van alle pacotilles resulteerde in het hoge bedrag van 372.264 Znd.fl. of $30,6 \%$ van de totale scheepslading. De private inkomsten van de andere supercargo's bedroegen slechts $32.760 \mathrm{Znd}$.fl., terwijl Hume en Harrison 339.554 Znd.fl. konden opstrijken. Dit betekende voor hen een netto-winst van liefst 173.106 Znd.fl. ! ${ }^{72}$. Als commissionarissen brachten ze nog een textiellading mee voor twee Franse handelaars en verkochten deze goederen in Oostende ${ }^{73} \&^{74}$.

71. In 1723 verdiende Charles Pike, als eerste supercargo op de Chinavaarder «Marquis de Prié», 185.315 Znd.fl.w.g., (een klein fortuin in die tijd). (K. DEGRYSE, op. cit. p. 308).

72. De participanten in de "Carel den Sesden" kregen een dividend waarop ze $104 \%$ winst hadden. Het was de eerste (en de laatste) maal dat men zo'n hoge winstmarge noteerde bij een Indië-uitreding. Dit werd de impuls om de GIC-handel te concentreren op de Bengaalse textielmarkt. Bovendien startte Hume, tijdens zijn verblijf in Bengalen, al onderhandelingen over het bekomen van een factorijconcessie.

73. C. GILL, op. cit. p. 47-50. Enkel Thomas Hall en Charles Pike, beiden aktief in de China-trafiek, wisten zich ook op dezelfde wijze te verrijken.

74. Deze handelaars waren de la Plussinais uit St.-Malo en Morellet uit Le Havre. 
De supercargo's gebruikten ook bodemarij-contracten om hun private handel te financieren. We beschikken over weinig gedetailleerde informatie betreffende dit aspect van de overzeese handel op de Oostendse Indiëvaarders, maar het was zeer courant om op deze wijze de supercargo's het nodige kapitaal te bezorgen. Op deze manier tekende Hume een bodemarij-brief van P.J. Cloots waardoor hij over $3.000 \mathrm{Znd} . f 1$. aan $30 \%$ kon beschikken, bij zijn reis met de «Stadt Weenen» ${ }^{75}$.

Bij de GIC werd officieel het pacotille-systeem verboden, maar de compagnie was verplicht private handel toe te staan om valabele supercargo's te kunnen engageren. We mogen wel zeggen dat de pacotilles op de GIC-schepen heel wat kleiner bleken dan tijdens de vooruitredingen ${ }^{76}$.

Onder de weinige supercargo's die fortuin maakten in Oostendse dienst, is de carrière van Alexander Hume opvallend. Hij bekleedde de post van gouverneur der GIC-factorijen (Banquibazar en Cabelon) tussen 1726 en 1731 . Voornamelijk door zijn toedoen groeide Banquibazar uit tot een kleine handelsstad ${ }^{77}$. Nadien keerde hij naar Engeland terug, waar hij verrassend snel verkozen werd tot directeur binnen de East India Company. Ook promoveerde hij tot lid van het «Secret Committee». Verscheidene jaren zetelde hij in het Lagerhuis. In 1739 kocht hij het landgoed Wormley in Hertfordshire ${ }^{78}$.

Tijdens de laatste bestaansjaren van de GIC verlieten talrijke supercargo's en zeelui - zowel Zuidnederlanders als vreemdelingen - onze gewesten en traden in dienst van de Zweedse en Deense compagnieën. De «Oostendenaars» hadden immers ervaring in Oost-Indiëhandel $^{79}$. Enkele supercargo's in Deense dienst konden

75. C. KONINCKX : Zuidnederlandse deelname... p. 132-133. Bodemarijcontracten kwamen zeer vaak voor in de Scandinavische compagnieën.

76. K. DEGRYSE, op. cit. p. 309-310.

77. L. BOEVA, op. cit. p. 121.

78. C. GILL, op. cit. p. 46-47.

79. RAK/Asiatisk Kompagni no 646, Roullebog 1723-1752 en C. KONINCKX, op. cit. p. 126. De Deense Aziatische Compagnie engageerde in de periode 1730-1740 9 supercargo's en officieren die voorheen diende bij de GIC. 
een loopbaan uitbouwen vergelijkbaar met die van Alexander $\mathrm{Hu}$ $\mathrm{me}^{80}$.

\section{BIJLAGE 1}

\section{DE WINSTEN}

\begin{tabular}{|c|c|c|c|}
\hline Schip & Bestemming & Winst/Verlie & \\
\hline Charles Galleye (1715) & Malabar, Goa, Surate & +100 & $\%$ \\
\hline Sint-Mattheus (1715) & Surate & +100 & $\%$ \\
\hline Prins Eugenius (1717) & Malabar & $?$ & \\
\hline Keyser Carolus VI (1718) & Malabar en Coromandel & -50 & $\%$ \\
\hline Keyserinne Elisabeth (1718) & Moka en Calicut & $+87,30^{\circ}$ & $\%$ \\
\hline Prins Eugenius (1719) & Malabar en Surate & $-63,78$ & $\%$ \\
\hline Marquis del Campo (1719) & Malabar en Surate & -60 & $\%$ \\
\hline Concordia (1719) & Malabar, Goa, Surate & $+1,75$ & $\%$ \\
\hline Stahremberg (1719) & Malabar en Surate & $-30,1$ & $\%$ \\
\hline Stadt Oostende (1720) & Coromandel & $-67,6$ & $\%$ \\
\hline Stadt Weenen (1720) & Coromandel en Bengalen & $+56,6$ & $\%$ \\
\hline Flandria $(1720)$ & Borneo, Surate, Moka & -60 & \\
\hline Keyserinne Elisabeth (1720) & Moka & $-16,25$ & $\%$ \\
\hline Stadt Gendt $(1720)$ & Moka, Surate, Goa & +48 & $\%$ \\
\hline Sint-Pieter (1721) & Malabar, Goa, Surate & $+12,81$ & $\%$ \\
\hline Graef van Lalaing (1721) & Malabar, Surate, Moka & $+17,8$ & $\%$ \\
\hline Stadt Brugghe (1721) & $\begin{array}{l}\text { Maledives, Malabar, } \\
\text { Coromandel }\end{array}$ & $-55,2$ & $\%$ \\
\hline Keyserinne Elisabeth (1722) & Moka & $?$ & \\
\hline Carel den Sesden (1723) & Coromandel en Bengalen & $+104,37$ & $\%$ \\
\hline
\end{tabular}

80. Pieter van Hurk, voornaamste supercargo op de eerste Deense Chinavaarder, werd een van de directeurs binnen de Deense compagnie. Guillaume De Brouwer, een Oostendenaar, was de bestbetaalde kapitein-supercargo van deze compagnie tijdens de jaren 1730-1738. 


\section{Opmerkingen}

Deze netto-winsten zijn afgeleid van de dividenden die aan de aandeelhouders werden uitbetaald.

Het totaal gemiddelde geeft misschien wel een vertekend beeld, want drie schepen, de «Prins Eugenius» (1719), de «Stadt Oostende» (1720) en de «Flandria» (1720) werden gekaapt of geconfisceerd, één schip, de «Keyserinne Elisabeth» (1720) verging op de rede van Oostende, en een andere bodem, de «Stadt Brugghe» (1721), vertrok helemaal niet. Indien wij deze vijf schepen weglaten, bekomen we een gemiddelde winstmarge van \pm $32,39 \%$.

Over de «Prins Eugenius» weten we enkel dat het in 1717 een zeer winstgevende reis maakte. Het verlies van de gekaapte Mokavaarder «Keyserinne Elisabeth» (1722) was aanzienlijk. We vermoeden wel dat de participanten in deze uitreding een deel recupereerden via de verzekeringsuitkeringen.

R. Baetens vermeldt in zijn bijdrage over «Investering en rendement bij de Generale Indische Compagnie : de handel op Bengalen vergeleken met de Chinahandel» in : Album Charles Verlinden (Gent, 1975), op p. 19, ook cijfers betreffende het rendement van deze uitredingen, doch deze zijn zeer onvolledig. 


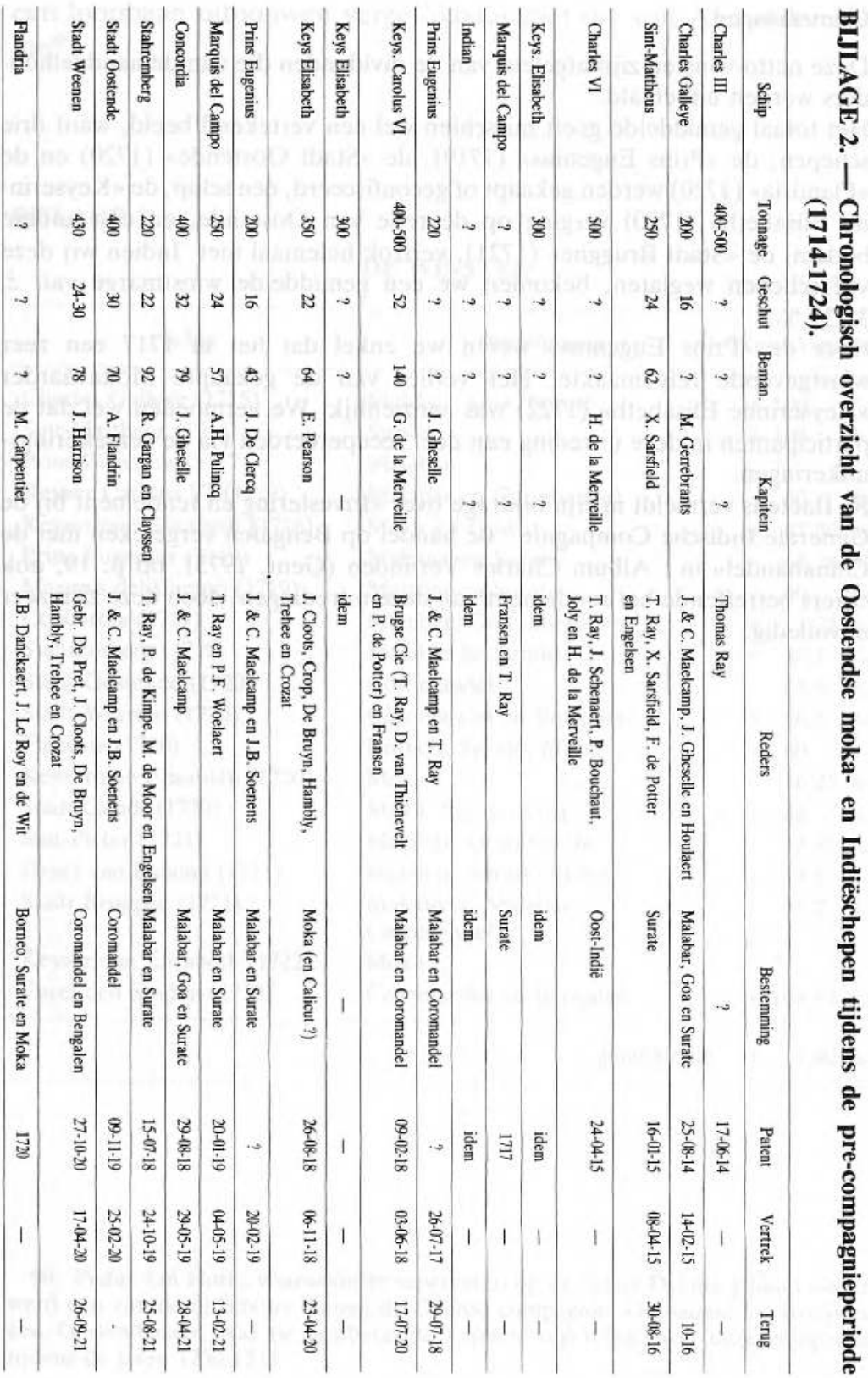




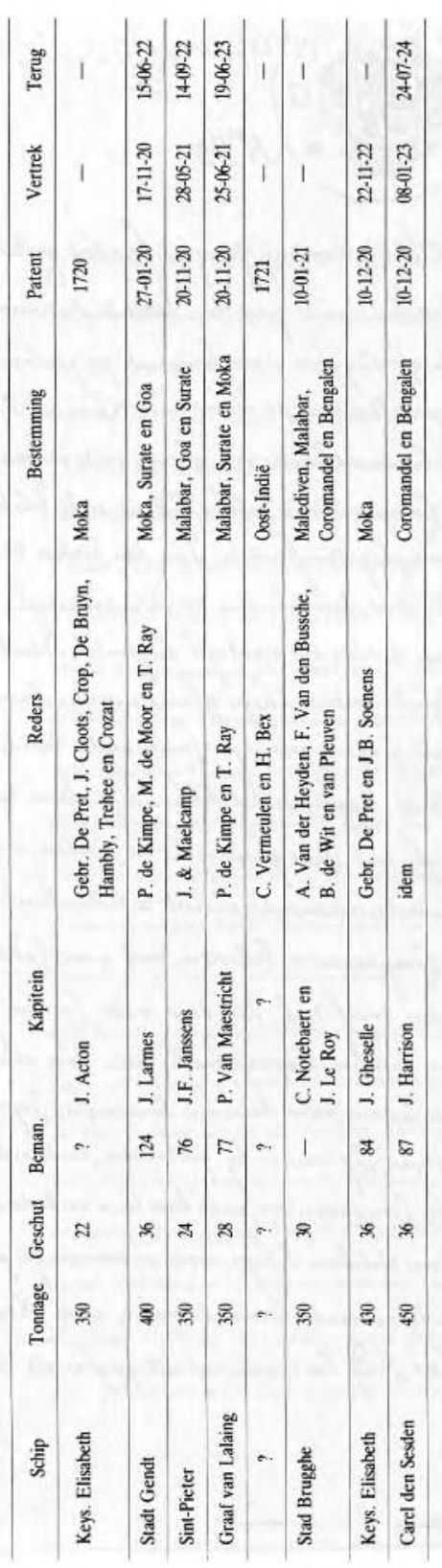




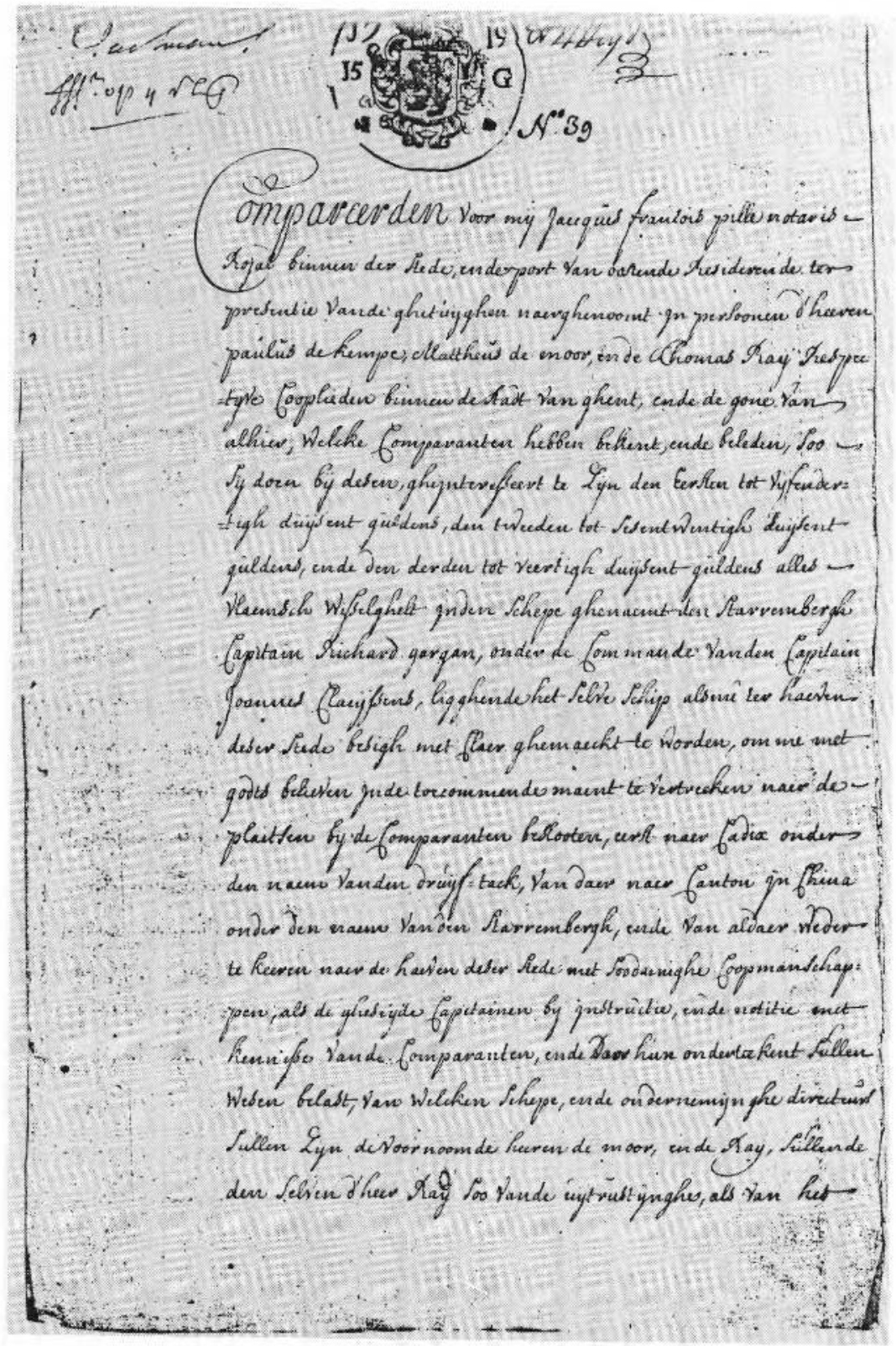




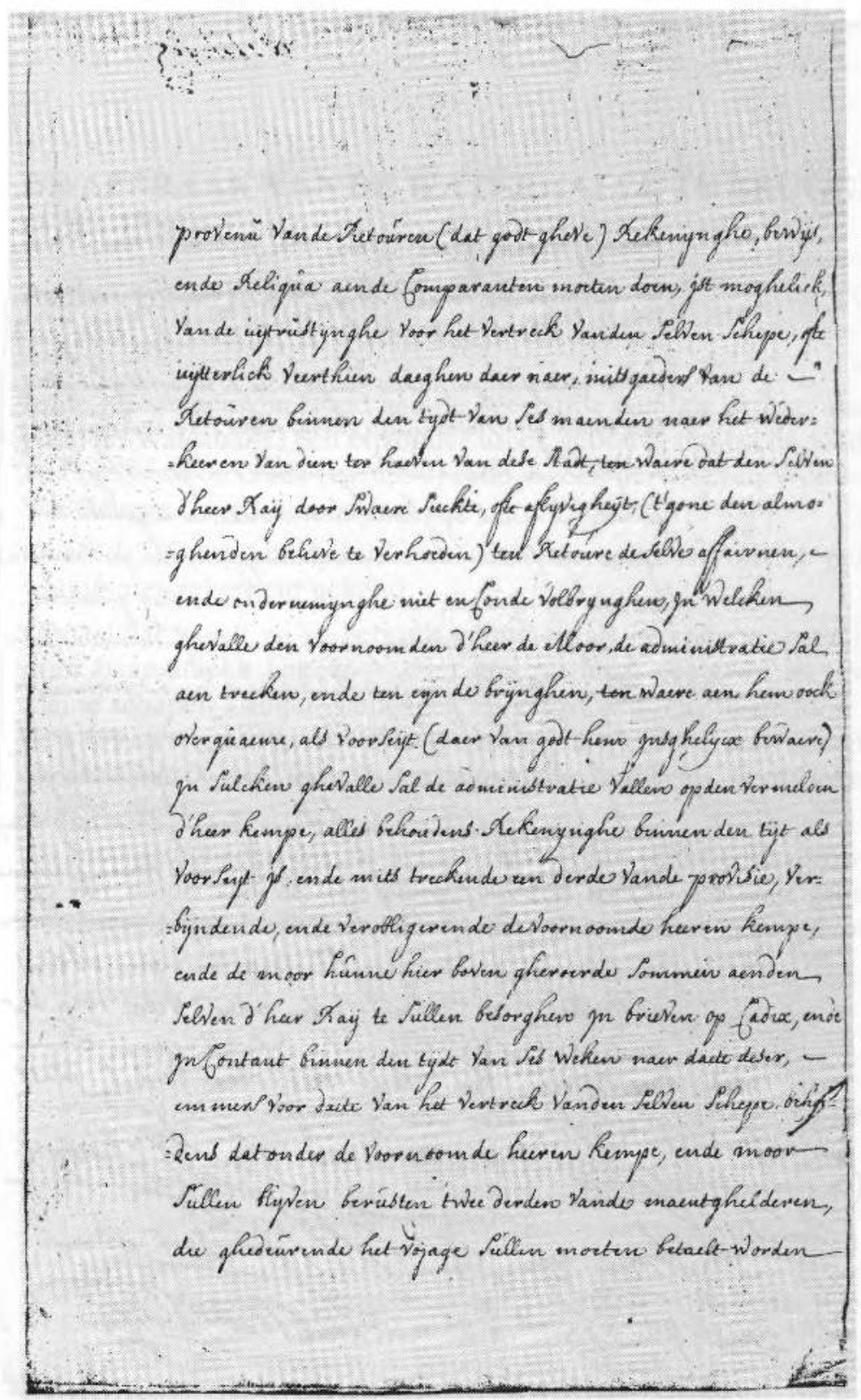




\section{De handelaars en supercargo's}

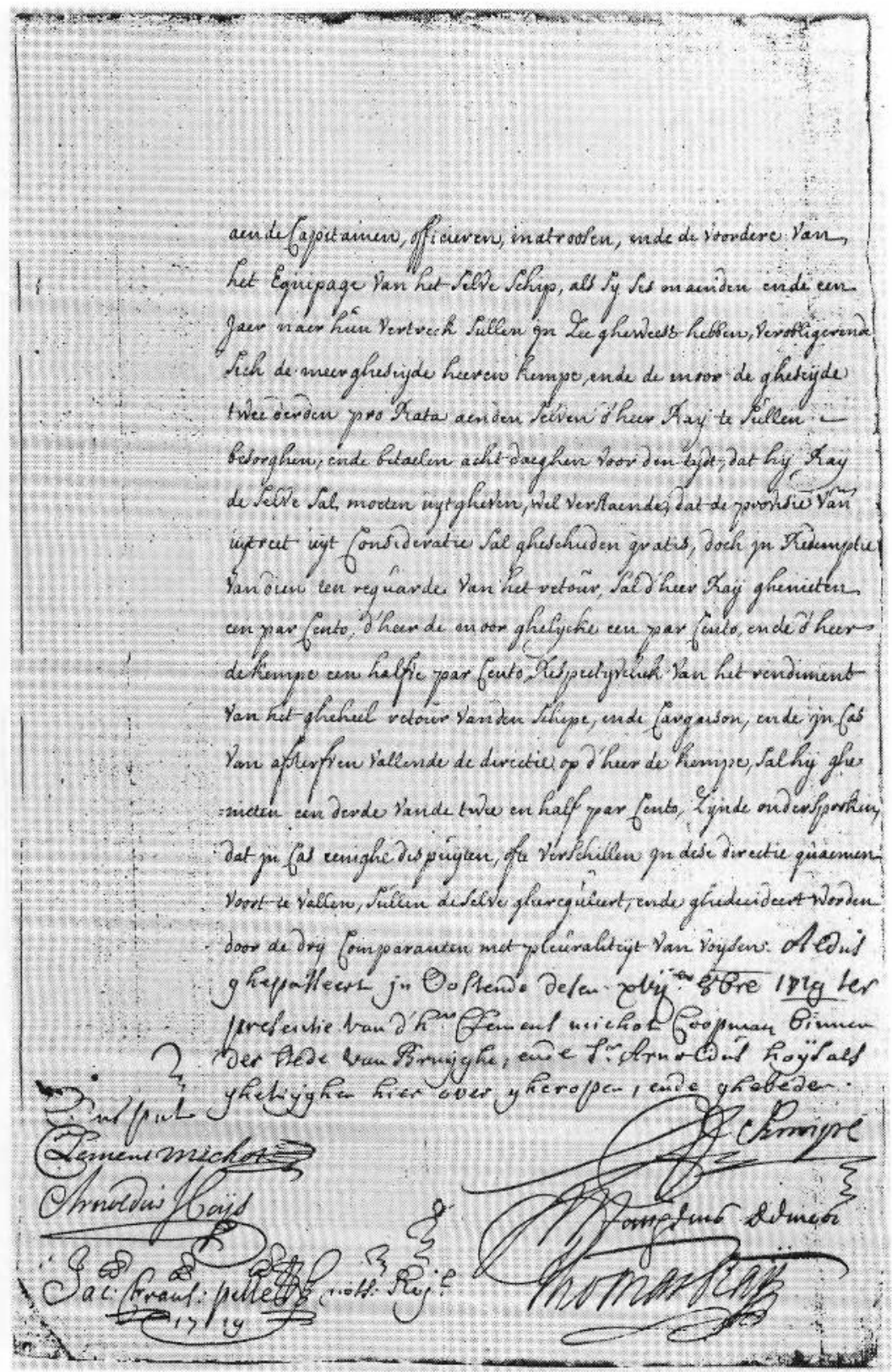

